\title{
The importance of wind-blown snow redistribution to snow accumulation on Bellingshausen Sea ice
}

\author{
Katherine C. LEONARD, ${ }^{1,2}$ Ted MAKSYM ${ }^{3}$ \\ ${ }^{1}$ WSL Institute for Snow and Avalanche Research SLF, Flüelastrasse 11, CH-7260 Davos-Dorf, Switzerland \\ E-mail: leonard@slf.ch \\ ${ }^{2}$ Lamont-Doherty Earth Observatory, Columbia University, Palisades, NY 10964-8000, USA \\ ${ }^{3}$ Natural Environment Research Council, British Antarctic Survey, Madingley Road, Cambridge CB3 OET, UK
}

\begin{abstract}
Snow distribution is a dominating factor in sea-ice mass balance in the Bellingshausen Sea, Antarctica, through its roles in insulating the ice and contributing to snow-ice production. The wind has long been qualitatively recognized to influence the distribution of snow accumulation on sea ice, but the relative importance of drifting and blowing snow has not been quantified over Antarctic sea ice prior to this study. The presence and magnitude of drifting snow were monitored continuously along with wind speeds at two sites on an ice floe in the Bellingshausen Sea during the October 2007 Sea Ice Mass Balance in the Antarctic (SIMBA) experiment. Contemporaneous precipitation measurements collected on board the RVIB Nathaniel B. Palmer and accumulation measurements by automated ice massbalance buoys (IMBs) allow us to document the proportion of snowfall that accumulated on level ice surfaces in the presence of high winds and blowing-snow conditions. Accumulation on the sea ice during the experiment averaged $<0.01 \mathrm{~m}$ w.e. at both IMB sites, during a period when European Centre for Medium-Range Weather Forecasts analyses predicted $>0.03 \mathrm{~m}$ w.e. of precipitation on the ice floe. Accumulation changes on the ice floe were clearly associated with drifting snow and high winds. Drifting-snow transport during the SIMBA experiment was supply-limited. Using these results to inform a preliminary study using a blowing-snow model, we show that over the entire Southern Ocean approximately half of the precipitation over sea ice could be lost to leads.
\end{abstract}

\section{INTRODUCTION}

Snow plays a critical role in controlling Antarctic sea-ice mass balance. It insulates the ice, limiting thermodynamic ice growth (Maykut and Untersteiner, 1971; Wu and others, 1999; Fichefet and others, 2000), but also promotes ice growth through the formation of snow ice (Maksym and Jeffries, 2000; Jeffries and others, 2001). Snow also plays an important role in controlling ice surface properties (Haas and others, 2001) and in shaping sea-ice ecosystems (Ackley and Sullivan, 1994). Despite this, quantification of precipitation and snow-ice formation has been elusive due to a lack of direct observations of snowfall in the Antarctic sea-ice zone (Maksym and Markus, 2008) and a poor understanding of the processes that control snow accumulation there. Key among these processes is wind transport, erosion and redistribution of snow, and the resulting losses to leads. Few studies have examined the role of drifting and blowing snow on sea-ice mass balance (e.g. Eicken and others, 1994; Déry and Tremblay, 2004). However, simple models suggest that it could have a substantial impact on snow-ice formation rates (Fichefet and Morales Maqueda, 1999; Maksym and Markus, 2008). Eicken and others (1994) used a parameterization of near-ground snow transport to estimate that $0.004 \mathrm{~m}$ of snow per day might be eroded and lost into leads spaced $1000 \mathrm{~m}$ apart in the Weddell Sea on rare high-wind days. Déry and Tremblay (2004) showed that even for higher rates of blowing-snow mass transport, $60-100 \%$ of all mass in transport by the wind was lost into leads of a variety of widths and spacings.

Redistribution of snow by the wind is commonly observed over sea ice and is known to result in irregularly distributed snow accumulation over ice floes and the loss of snow into leads (Massom and others, 2001). Snow transported by the wind tends to be deposited preferentially in the lee of topographic disturbances such as ridges and eroded preferentially from flat areas where an adequate fetch to establish wind erosion exists (lacozza and Barber, 2010). The transport of snow by the wind includes two principal modes of particle motion: (1) saltation, a near-surface hopping movement that tends to be restricted to the larger grains in a typical snow size distribution; and (2) suspension, in which finer grains become entrained in the wind (Bagnold, 1954). The mass transport of snow in saltation increases gradually at high wind speeds, but the mass transport of snow in suspension can increase dramatically as particles are lofted to high elevations when transport is continuous over a long snow-covered fetch (Pomeroy and Male, 1992). Sublimation of blowing snow quickly saturates initially dry air in the lowest $10 \mathrm{~m}$ of the atmosphere during blowing-snow events (Mann and others, 2000) and is also inhibited in the vapor-saturated air above sea ice (Andreas and others, 2002). However, in areas with long fetch and vertically well-developed snow plumes, sublimation can significantly diminish the total mass transport of blowing snow in the relatively dry air at higher elevations (Bintanja and Reijmer, 2001).

Numerous studies of the initiation of drift have led to relationships describing the wind stress or friction velocity, $u_{\star}$, on a snow surface above which snow is likely to be mobilized. Li and Pomeroy (1997) used drifting-snow data from a variety of locations and conditions to present evidence that this threshold friction velocity for drift varies with air temperature due to snow surface morphology changes and more rapid sintering of snow grains at warm temperatures. Air temperature also influences the mass transport of snow in suspension by increasing atmospheric density at lower air temperatures, reducing the mixing ratio 
of blowing snow (kg snow/kgair) for a given particle concentration of snow. Subsequent studies at specific sites have found varying levels of agreement with the $\mathrm{Li}$ and Pomeroy (1997) parameterization, probably due to locally distinct snow properties. Savelyev and others (2006) note that additional confusion may arise when analyzing field data, as the wind speed necessary to sustain transport is lower than that required for its initiation.

In the present study we use the Li and Pomeroy (1997) parameterization for drift threshold because the Antarctic seasonal ice zone is a relatively warm maritime environment with a range of snow surface morphologies (Massom and others, 2001). Rain-on-snow events, surface melt and the formation of ice layers will all act to limit the ability of the wind to erode older snow. This 'locking-up' of the snow can significantly limit its availability for wind transport (Sturm and others, 1998).

Precipitation over the Southern Ocean sea-ice zone is widely presumed to be higher than over the Antarctic continent (e.g. Bromwich, 1988), but field validation data of the sort traditionally used to confirm accumulation rates over the continent (systematically distributed snow pits and ice cores, ice-penetrating radar) are unavailable over sea ice. Observations of snow depth on Antarctic sea ice are limited to focused studies of small areas (e.g. this study) or 'ship of opportunity' observations of conditions along the track of research ships (Worby and others, 2008). The former are extremely limited, whilst the latter are often biased towards ice conditions in navigable waters, with thinner ice and a larger lead fraction than may be representative for a region as a whole. Satellite methods for snow-depth retrieval show promise (Markus and Cavalieri, 1998) but are affected by several basic problems that are also present in ship-based estimates. Spot observations of snow depth tend to be low because there are a variety of processes that decrease the mean snow depth on the ice. Maksym and Markus (2008) noted that month-to-month changes in satellite snow depth were much smaller than estimated snowfall, and attributed these differences to snow-ice formation and reductions in the mean snow depth due to divergence and new snow-free ice formation. Whilst few modeling studies report snow depth on sea ice, those that do tend to exhibit deeper snow than is actually observed (e.g. Fichefet and Morales Maqueda, 1999; Wu and others, 1999; Fichefet and others, 2000), suggesting that wind erosion and subsequent loss to leads may be important.

We present direct observations of wind-blown snow made during the Sea Ice Mass Balance in the Antarctic (SIMBA) project in the Bellingshausen Sea aboard the RVIB Nathaniel B. Palmer (NBP) between 1 September and 31 October 2007. Between 28 September and 24 October, the ship drifted with a large $(>2 \mathrm{~km})$ ice floe (Lewis and others, in press). Observations of snow accumulation and wind transport on the floe are compared with estimates of precipitation from atmospheric reanalysis. Wind erosion of snow is also modeled with a blowing-snow model. The comparison between model results and the observations is then used to inform an estimate of the large-scale impact of blowing-snow losses on accumulation over Antarctic sea ice.

\section{METHODS}

During the SIMBA experiment in October 2007 the precipitation, accumulation and redistribution of snow were monitored continuously on and over a large ice floe in the western Bellingshausen Sea (Fig. 1) between 1 and 23 October 2007. Vertical profiles of wind and drifting snow were measured at two research sites on the floe separated by approximately $1 \mathrm{~km}$. These two level-ice sites were selected for intense study of a variety of subjects during the drift experiment due to their contrasting snow and ice properties (Lewis and others, in press). Each research site included one or more ice mass-balance buoys (IMBs). The timing and intensity of precipitation were measured on the NBP during the entire research cruise using a photoelectric particle counter. Additional meteorological data collected on the ice floe and on the ship were analyzed by Vancoppenolle and others (in press).

The first IMB (Fig. 1) was installed on the ice floe at site 1 on 1 October, 1 day prior to the installation of the driftingsnow station at that site, and remained with the ice floe following the departure of the NBP. An IMB was installed at site 2 on 5 October, 1 day prior to the installation of the drifting-snow station at that site, and was removed on 23 October, 1 day after the removal of the snow station. On 12 October, a second IMB was added to site 1 (approximately $100 \mathrm{~m}$ from the first) and remained with the ice floe following the experiment. These buoys consist of an array of instruments monitoring ice thickness changes, ice temperature, and the air and ocean properties that may be causing those changes in thickness (Richter-Menge and others, 2006). The net accumulation of snow on the ice floe was recorded by these IMBs using Campbell SR50 sonic distance-measuring devices mounted on a short mast to record changes in distance between the device and the snow surface, as described in detail by Knuth and others (2010). Data from each IMB were recorded and transmitted over the Advanced Research and Global Observation Satellite (ARGOS) system every 2 hours until break-up of the floe and loss of the instruments. Post-processing of the snow height data was performed to adjust for changes in the speed of sound (and apparent distance to the snow surface) as a function of air-temperature fluctuations around the experiment mean of $-10^{\circ} \mathrm{C}$. Relative humidity was recorded $2 \mathrm{~m}$ above the ice floe at a separate meteorological station and found by Vancoppenolle and others (in press) to be at or near saturation during the experiment.

Stations measuring vertical profiles of wind and drifting snow were sited near each of the two principal on-ice research sites (Fig. 1). These stations each included two photoelectric sensors (Wenglor YH03NCT8) and three anemometers (RM Young Wind Sentry). The photoelectric sensors detected the number of snow particles passing through a narrow beam of $655 \mathrm{~nm}$ light each second. The total snow particle count was recorded every $10 \mathrm{~s}$, along with mean wind speeds and gusts during that interval recorded by the three low-threshold mechanical anemometers. The anemometers were installed at heights of approximately $0.5,1.5$ and $2.5 \mathrm{~m}$ on each station, and the elevation of all instruments above the snow surface was measured periodically. The stations were on the ice floe between 2 and 17 October 2007 at sites 1 and 6 and 22 October 2007 at site 2 .

The friction velocity $u_{\star}$ was calculated for each station by fitting a logarithmic wind profile to the recorded wind speeds. Icing of, and/or drifting-snow interference with, the lower anemometers was detected by comparing the observed $u_{\star}$ record with the wind-speed record of the anemometer at 

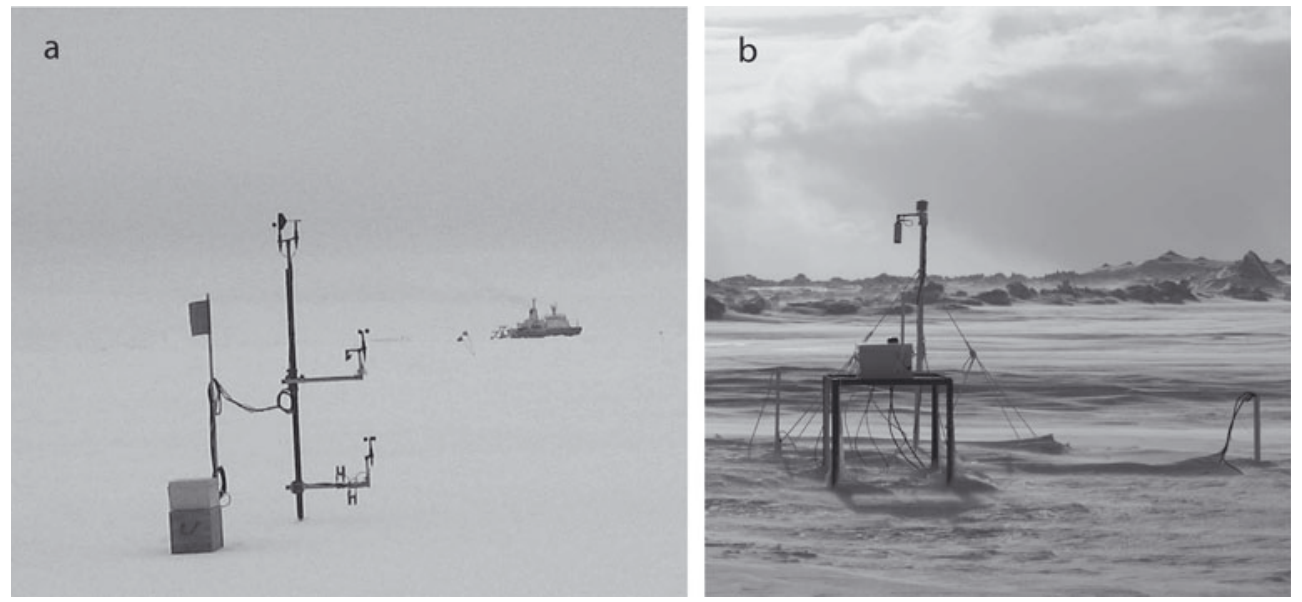

Fig. 1. Experimental configuration during the SIMBA drift experiment. The drifting-snow and accumulation measurements were collected at two research sites on the ice floe separated by approximately $1 \mathrm{~km}$. Each site included (a) a drifting-snow station and (b) an ice mass-balance buoy (photograph by M. Lewis). Precipitation was measured using a photoelectric particle counter mounted on the leading edge of the NBP's lookout tower approximately $30 \mathrm{~m}$ a.s.l. (see background on right-hand side in (a)).

the highest elevation and flagging those instances when the observed $u_{\star}$ values predicted $2.5 \mathrm{~m}$ wind speeds that were substantially $\left(>5 \mathrm{~m} \mathrm{~s}^{-1}\right)$ different from the observed values. The $10 \mathrm{~s}$ data recorded by the snow stations were resampled onto the same 2 hour intervals as the IMB data for ease of comparison between the datasets. In the resampling process, the frequency of drift detection during each interval was calculated as a fraction of the total number of possible drift measurements sampled during the 2 hour interval.

Precipitation was recorded on board the NBP approximately $30 \mathrm{~m}$ above the ship's waterline using an identical photoelectric particle counter to those employed to measure drifting snow, as described by Leonard and Cullather (2008). These devices record snow particles $>100 \mu \mathrm{m}$ in size that interrupt a beam, but do not discriminate between snow particle sizes above that threshold (as described for a similar sensor by Brown and Pomeroy, 1989). This means that the precipitation record cannot be translated directly into water equivalent, although the timing and relative intensity of precipitation recorded on the ship can be compared with atmospheric model predictions of precipitation at the ship's location. In the present study, operational precipitation forecasts from the European Centre for Medium-Range Weather Forecasts (ECMWF; Klinker and others, 2000) were compared with the shipboard total particle count for each day of the cruise. The operational forecast fields at a horizontal resolution of $1.125^{\circ} \times 1.125^{\circ}$ are an accumulation of the 12-36 hour period of the daily forecast that began at 12.00 UTC the previous day. Daily total snow counts were compared with the modeled precipitation for the gridcell the ship occupied at 12.00 UTC on each day of the cruise. Instantaneous values of pressure and temperature were shown to correspond well between the ship and the model by Leonard and Cullather (2008), supporting the decision to compare our ship-based measurements with ECMWF forecast precipitation.

We use a numerical atmospheric boundary-layer model of blowing snow (Leonard and others, 2008) forced with the wind and temperature conditions experienced during the SIMBA experiment to calculate the potential mass loss from the ice floe due to drift. This model replicates the twodimensional evolution in time and space of sublimating snow-filled air over a snow-covered surface by solving four advection-diffusion equations for air temperature, watervapor mixing ratio, particle number concentration and blowing-snow mixing ratio. The model's operation was restricted in the present application to wind speeds above the Li and Pomeroy (1997) temperature-dependent threshold. The mass transport $Q_{\mathrm{t}}\left(\mathrm{kg} \mathrm{m}^{-1} \mathrm{~s}^{-1}\right)$ calculated by the model is the column-integrated product of the blowingsnow mixing ratio ( $\mathrm{kg} \mathrm{snow} / \mathrm{kg}$ air) and the air mass moving through a $1 \mathrm{~m}^{2} \times 1 \mathrm{~km}$ high column (Déry and Tremblay, 2004; Leonard and others, 2008). The model calculates the maximum transport possible for the defined boundary conditions. For this study, the model was run from an initially calm state with snow resting on a flat surface at various wind speeds and air temperatures, with an integration time-step of $10 \mathrm{~s}$ and a horizontal resolution of $1 \mathrm{~m}$. The mass transport was sampled at run times corresponding to a $1 \mathrm{~km}$ fetch, as this was a reasonable assumption for the fetch upwind of either snow station on the SIMBA ice floe. For example, at a wind speed of $10 \mathrm{~m} \mathrm{~s}^{-1}$, the value of $Q_{t}$ calculated after $100 \mathrm{~s}$ was used. Although the model can be used to calculate sublimation of blowing snow, this feature was not used in the present study due to the saturated nature of the near-surface atmosphere.

The modeled values of mass transport were applied to the distribution of wind speeds measured on the ice floe to calculate a maximum possible drift loss from the floe during the experiment. To place the results at the SIMBA site in context, we estimated mass loss of snow from sea ice around Antarctica for September 2007 using the values of $Q_{t}$ calculated for a $1 \mathrm{~km}$ fetch and the observation that the majority of mass remains low in the air column after such a short fetch. All snow in saltation will be lost into leads of $1 \mathrm{~m}$ or more width (Leonard and others, 2008), and the majority of the snow mass in suspension is also likely to fall out of suspension within a short distance.

For the regional study, we used mean daily wind speeds, precipitation and $10 \mathrm{~m}$ air temperatures from the ECMWF re-analysis (ERA) interim data to estimate the snow accumulation and wind-transported mass flux over all ice-covered areas of the Southern Ocean. This sea-ice mask was defined based on passive microwave observations using 


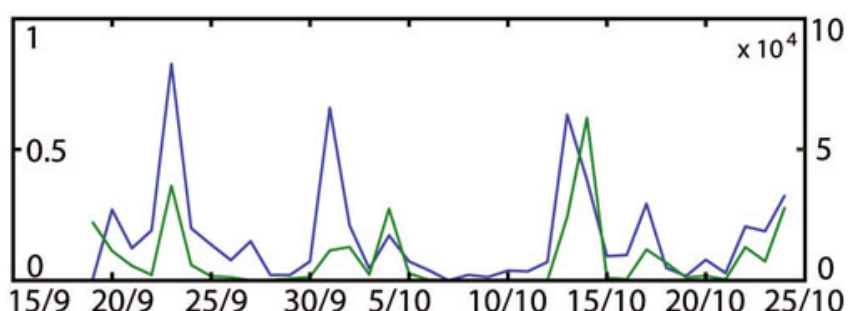

Fig. 2. Precipitation during SIMBA from shipboard measurements (green) and ECMWF model forecasts (blue). Dates are day/month. The shipboard measurements in green are the daily total number of snowflakes counted on board the NBP. The net precipitation from ECMWF in blue is in mmw.e. The record shown here also demonstrates the good correspondence between the two records whilst the ship was transiting the Southern Ocean and northern Bellingshausen Sea prior to the SIMBA drift station (28 September24 October).

the Bootstrap 2 algorithm (Comiso and Nishio, 2008). Rather than using a distribution of lead spacings and widths (poorly known for the Antarctic), we follow Eicken and others (1994) in assuming a lead spacing of $1 \mathrm{~km}$, with all blowing snow from a given ice floe lost into the adjacent lead. To account for the 'lock-up' of snow after deposition, only snow that has fallen in the past 2 days (as determined by the ERA interim data) is permitted to erode. Whilst this is a somewhat simplistic treatment, our goal is to provide a first-order assessment of the importance of blowing-snow transport in sea-ice mass balance.

\section{RESULTS}

Net precipitation over the study ice floe during the experiment (1-23 October) from the ECMWF operational forecasts equalled $0.032 \mathrm{mw}$.e. As shown in Figure 2, the forecast precipitation coincided with the timing and relative magnitude of the observed precipitation before and during the drift experiment, but the net water equivalent was not measured and hence could not be compared. As shown in this plot, there was a 3 day interval in the middle of the experiment with negligible measured snowfall, but precipitation was detected on all other days. Daily total measured snow count is compared with the ECMWF daily precipitation forecast in Figure 2 and shown as a 2 hour average count per second in Figure $3 \mathrm{a}$.

The snow depths recorded by the three IMBs that were on the ice floe during the SIMBA drift experiment are shown in Figure $3 \mathrm{~b}$, plotted as thickness above the minimum snow depth in each record. Between 1 and 22 October the net change in snow depth was negligible for the first IMB at site 1 and for the IMB at site 2 between 5 and 22 October. The second IMB at site 1, in place between 12 and 22 October, recorded a net increase in snow depth of $0.03 \mathrm{~m}$ (approximately $0.01 \mathrm{~m}$ w.e.) as a result of a storm on 19-20 October. A steep rise in snow depth at site 2 on 22-23 October is interpreted as settling of the instrument mast during a partial flooding of the ice floe that preceded removal of that IMB. The increases and decreases in snow height are clearly related to the precipitation (Fig. 3a), friction velocity (Fig. 3c) and drifting-snow records (Fig. 3d), as can be seen most easily towards the right side of those plots, during a heavy snow and wind storm. Snowfall under low-wind conditions led to accumulation on the ice floe, while high values of $u_{*}$

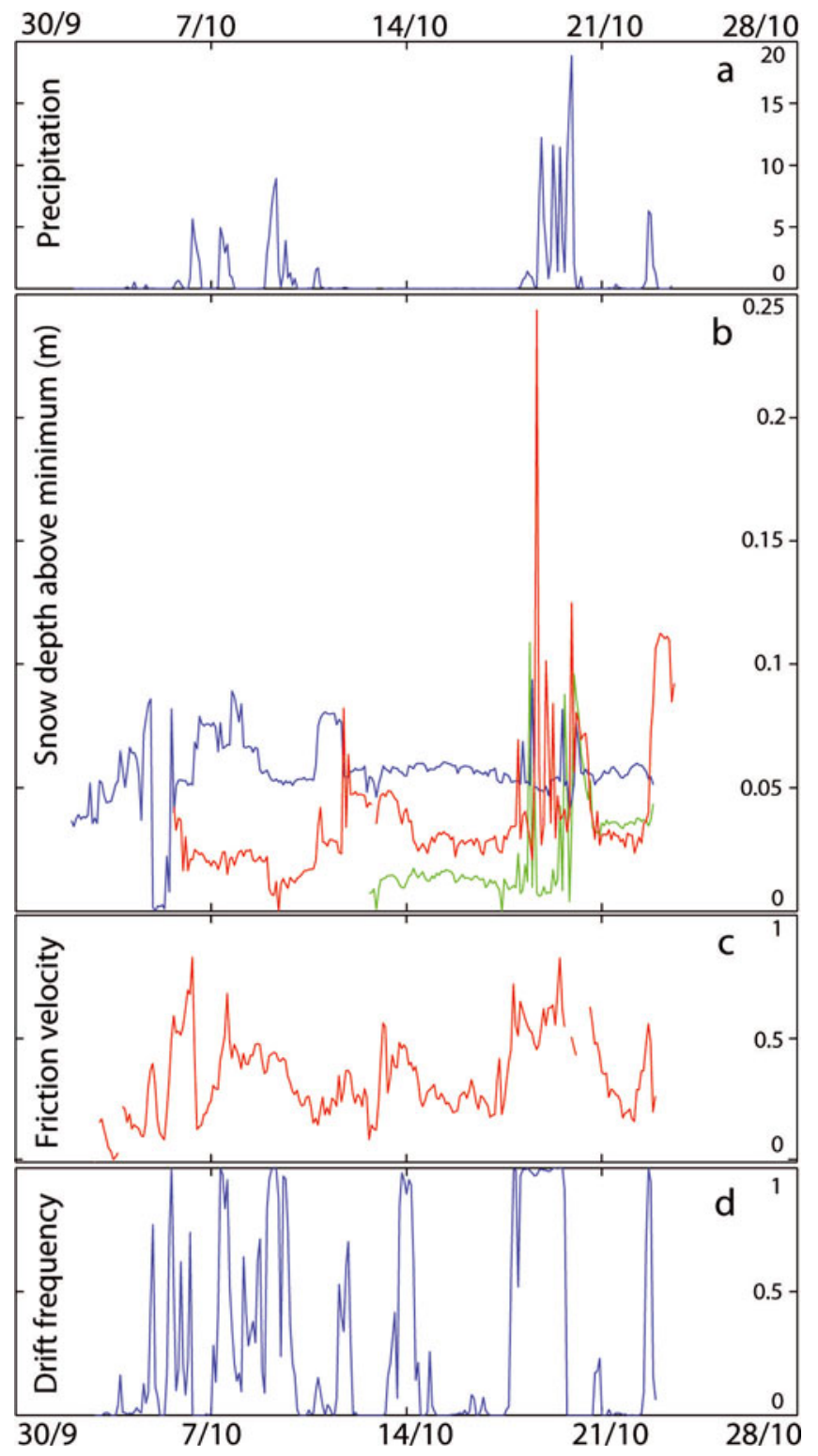

Fig. 3. Experimental results from the SIMBA drift experiment. Dates are day/month. (a) Two-hourly average precipitation rate measured on the NBP in counts per second. (b) Depth of snow on the ice floe measured by IMBs using acoustic depth sounders plotted relative to the minimum value for each series. The blue line shows the measurements from the first IMB deployed at site 1, the red line shows the single IMB at site 2 and the green line shows the second IMB at site 1. (c) Two-hourly average friction velocity $u_{\star}$ exerted on the snow surface calculated from measured wind profiles, corresponding to $10 \mathrm{~m}$ wind speeds between 0 and $25 \mathrm{~m} \mathrm{~s}^{-1}$. (d) Frequency of drifting-snow occurrence within each 2 hour interval.

corresponded with drifting snow and removal of accumulated snow.

Between the time of installation of the first IMB at site 1 on 1 October and removal of the IMB from site 2 on 23 October, there were 2582 hour intervals in which data were recorded. One or both snow stations recorded data during 242 of those time periods and both snow stations were operating between 6 and 17 October, simultaneously recording drift and wind data during 115 of the IMB recording intervals. The good correspondence between wind-speed and snowdrift measurements at the two stations when they were operating simultaneously led us to combine 
the data from the two stations into single records of $u_{\star}$ and drift frequency covering the full time series. Drifting snow was detected during $70 \%$ of the recording intervals. On average, drift occurred $38 \%$ of the time during those intervals, and in total snow was drifting $27 \%$ of the time during the SIMBA experiment. Figure 4 shows that although there was a strong tendency towards high drift frequency at high values of $u_{\star}$, many outliers exist.

The combined record of $u_{*}$ is slightly shorter than that of drift occurrence due to the exclusion of nine intervals during which the lower anemometer on the station at site 2 recorded slower than theoretically predicted wind speeds due to icing and/or clogging of the mechanical wind sensor with drifting snow. The drifting-snow threshold for an air temperature of $-20^{\circ} \mathrm{C}$, according to $\mathrm{Li}$ and Pomeroy (1997), is $u_{\star}$ equal to or greater than $0.3 \mathrm{~m} \mathrm{~s}^{-1}$. Of the 233 records for which we have friction velocity, we have plotted the drift frequency in Figure 4. More than $49 \%$ of these records experienced a mean $u_{\star}>0.3 \mathrm{~m} \mathrm{~s}^{-1}$, with $43 \%>0.35 \mathrm{~m} \mathrm{~s}^{-1}$. The mean drift frequency was $52.3 \%$. The mean drift frequency corresponding to $u_{\star}>0.35 \mathrm{~m} \mathrm{~s}^{-1}$ (the drift threshold for $-10^{\circ} \mathrm{C}$ ) was $58.2 \%$. This means that drift was occurring more than $50 \%$ of the time that wind speeds were high enough to move snow at low temperatures, and nearly $60 \%$ of the time that wind speeds exceeded the threshold corresponding to the mean air temperature during the experiment.

We modeled the potential mass transport of blowing snow, $Q_{t}$, using the mean observed air temperature of $-10^{\circ} \mathrm{C}$ and the distribution of wind speeds measured on the ice floe during the experiment. If drifting and blowing snow were present with mass concentrations developed over a $1 \mathrm{~km}$ upwind fetch at all times that wind speeds exceeded the drift threshold, an average of $0.068 \mathrm{~m}$ w.e. could have been lost from the SIMBA ice floe. However, if the ECMWF precipitation estimates are correct, then actual losses could have been no more than $2-3 \mathrm{~cm}$ w.e., or one-third to one-half the potential losses suggested by the blowing-snow model. This indicates that the mass transport of blowing snow was limited by the availability of recent precipitation. Older precipitation was either removed by the wind or became 'locked up', as suggested by Sturm and others (1998).

Precipitation losses due to blowing snow for the entire Southern Ocean during September 2007 were also modeled. Blowing-snow losses were computed over all icecovered waters at a $25 \mathrm{~km}$ resolution (corresponding to the standard Special Sensor Microwave/Imager grid) The blowing-snow mass transport corresponding to the ERA interim mean daily wind speed and $10 \mathrm{~m}$ air temperatures was allowed to remove precipitation falling on that day or 1 day earlier. This cut-off is broadly consistent with the observations made at the SIMBA site. In addition, to account for the fact that blowing snow was observed at SIMBA only half of the time that the model suggests winds were strong enough to produce blowing snow, the snow mass flux was scaled back by $50 \%$. Actual blowing-snow losses will depend on a number of poorly known factors, such as the history of the snowpack (which influences snow morphology and erodibility), ice morphology (which can retard loss to leads, if ridges trap the snow) and the width and distribution of leads. Our intent is not to provide precise values of these losses but to provide order-of-magnitude estimates to evaluate whether this process is significant enough to merit more detailed investigation.

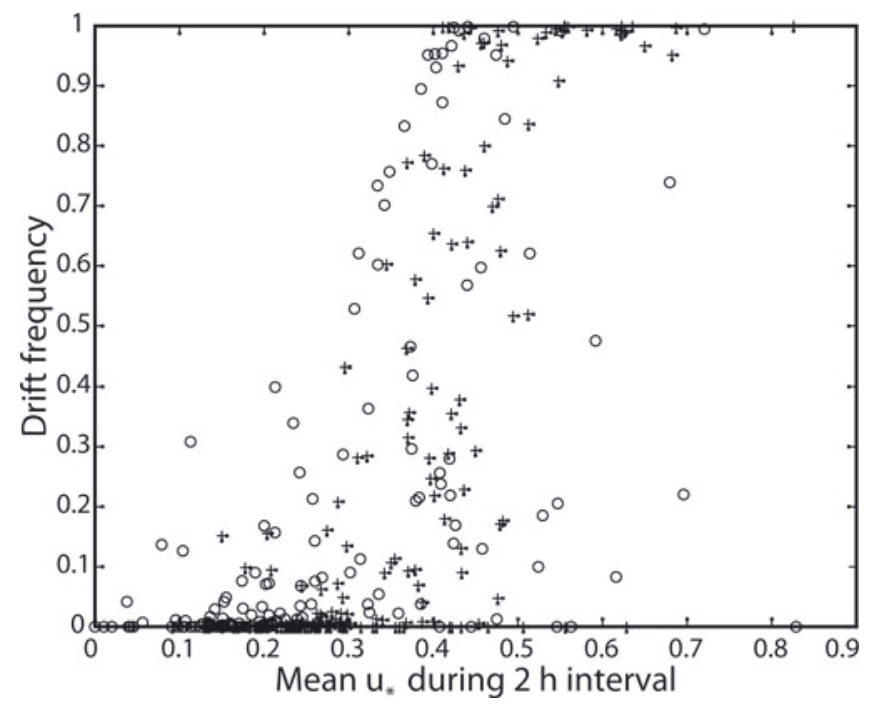

Fig. 4. Drifting-snow frequency vs friction velocity $u_{\star}\left(\mathrm{m} \mathrm{s}^{-1}\right)$ for the two snow stations on the SIMBA ice floe. Data from the site 1 station are shown as open circles; data from the site 2 station are shown as crosses.

Figure 5a shows the estimated accumulation (precipitation) from the ERA interim data, whilst Figure 5b shows our new estimated accumulation after accounting for loss of snow into leads through wind erosion. On average, precipitation over sea-ice-covered waters was $0.044 \mathrm{~m}$ w.e., whilst our new accumulation estimate averages $0.022 \mathrm{~m}$. Snow erosion losses are greatest in the outer pack, particularly in the Ross Sea and the East Antarctic between $90^{\circ} \mathrm{E}$ and $120^{\circ} \mathrm{E}$. In these regions, the effect of higher wind speeds outweighed the higher drift threshold and reduced transport rates caused by the warmer air temperatures. There are also substantial losses in the SIMBA area of the western Bellingshausen Sea, consistent with field observations. Nevertheless, heavy precipitation in this area outweighed losses due to drift, favoring higher than average accumulation. This may be more consistent with the relatively deep snow observed on other parts of the floe and regionally (Lewis and others, in press). Snow redistribution may be more important in the interior pack due to colder temperatures and lower precipitation rates close to the Antarctic continent. These results suggest that in these regions most of the precipitation could be lost to leads.

\section{DISCUSSION}

The accumulation of snow on level-ice areas of the SIMBA ice floe measured by the IMBs was negligible, with only one of three sensors detecting accumulation equaling $0.01 \mathrm{~m}$ w.e. during a synoptic event shortly before the end of the experiment. The other two sensors showed no net increase in snow depth. This lack of accumulation took place during a time when precipitation was measured almost every day on board the $N B P$, with a net water equivalent of $0.032 \mathrm{~m}$ of snow calculated to fall on the SIMBA ice floe from ECMWF operational forecasts. Almost all of the snow that fell was transported away by the wind and lost to leads or deposition in the lee of topography. The potential wind transport of snow modeled using the average air temperature and distribution of winds measured on the ice floe for the same period corresponds to a net erosion of $0.068 \mathrm{~m}$ w.e., more 


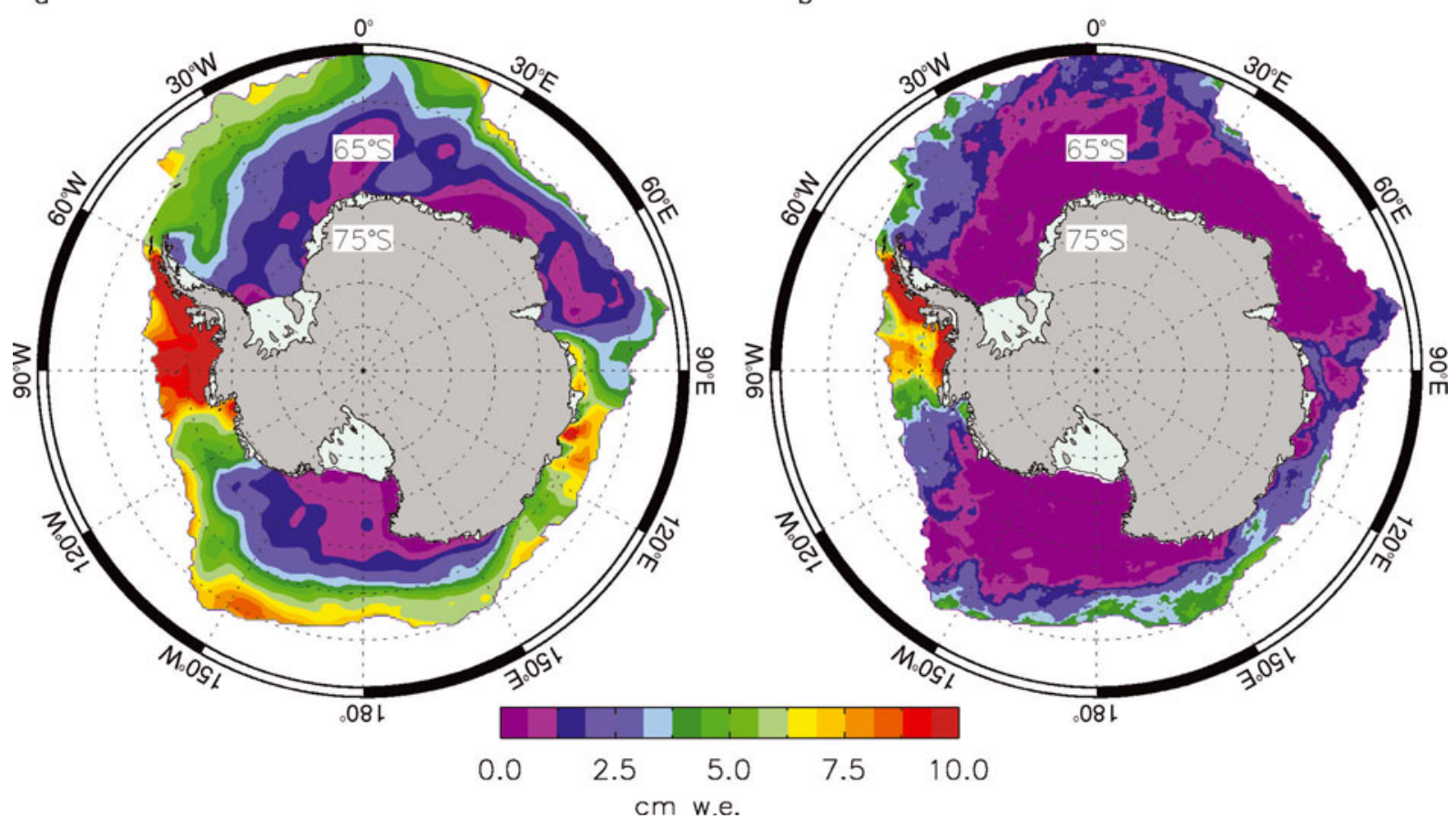

Fig. 5. Modeled snow accumulation on Antarctic sea ice for September 2007. (a) Accumulation determined from ERA interim precipitation; (b) same as (a) but including modeled losses of snow due to wind erosion.

than twice the precipitation and more than sufficient to reduce the ECMWF precipitation to the observed on-ice change in snow depth. The observed drift frequency of only $58 \%$ for wind speeds above the drifting-snow threshold indicates that there was an inadequate snow supply to permit drift at all times when the winds were sufficient to move snow. This suggests that drifting-snow transport during the SIMBA experiment was supply-limited (e.g. Macpherson and others, 2008).

The blowing-snow model used in this study was developed with the assumption of a uniformly erodible snow surface. In the model, snow is entrained from the ground into the air column at a rate necessary to replicate blowingsnow-saturated conditions observed in continental Antarctica, Wyoming, USA, and the Canadian Arctic (Xiao and others, 2000). Whilst Déry and Tremblay (2004) implemented several important modifications to the atmospheric boundary-layer model for application over Arctic sea ice, the simplifying assumptions about the snow surface were not altered. Snow on sea ice is often within a few ${ }^{\circ} \mathrm{C}$ of freezing, a precondition for rapid snow metamorphosis and grain sintering. Snow on Antarctic sea ice may also be flooded with sea water, and the underlying ice is often heavily ridged. Pressure ridges can limit entrainment by sheltering adjacent snow surfaces aerodynamically, leading to reduced values of mass transport relative to that which could develop over a uniform fetch. All of these factors contribute to intermittent drift on such surfaces. Because of this, the amount of snow entrained into the model is likely overestimated for such supply-limited surfaces. Further analysis of the profile measurements of blowing snow collected during this study will allow validation of the model for this environment. Scaling the net transport calculated by the model using the observed frequency of drift at SIMBA is a first attempt to include this effect in the regional analysis.
Using the model in a semi-heuristic fashion for the entire sea-ice zone during September 2007 suggests that wind-drift losses may equal half the total precipitation (averaged for the region, $0.044 \mathrm{~m}$ w.e. of precipitation fell, but only $0.022 \mathrm{~m}$ w.e. accumulated). This is much greater than the previous conservative estimate of Eicken and others (1994), largely because those authors only estimated the loss of saltating snow, whilst the model used in the present study includes the potentially much larger mass transport of snow in suspension. These results suggest that wind redistribution of snow is a major term in sea-ice mass balance. Whilst these results must be viewed with caution, they suggest possible solutions to several questions raised by Maksym and Markus (2008). First, blowing snow may be able to erode most of the precipitation in the interior pack (or at least redistribute it to ridged areas), thus providing an explanation for the low month-to-month changes in satellite-based snow-depth estimates without requiring prodigious snow-ice formation. Second, the high rate of blowing-snow loss in parts of the East Antarctic pack may help explain the generally low observed snow depths and snow-ice amounts in regions where atmospheric analyses suggest very high precipitation rates. For a similar rate of snow loss, Fichefet and Morales Maqueda (1999) modeled only modest changes in snow and ice volume vs a control run, but snow-ice formation rates were reduced by approximately $50 \%$. Of note, their results showed that the impact of drift losses was not comparable to an equivalent reduction in precipitation, in large part due to the impact on the freshwater balance of the ocean.

We stress several caveats to the regional snow-loss estimates. First, we used a nominal fetch, or lead spacing, of $1 \mathrm{~km}$. In reality, floes and lead spacings between them are better represented by size distributions that will vary temporally and with distance from the coast. In the late winter period analyzed here, it may be more appropriate to use a larger effective spacing in the interior pack, allowing 
greater mass transport of blowing snow over the increased fetch, but limiting losses to leads and polynyas near the continent. Second, the roles of snow surface morphology and ice property variations, particularly in the warm maritime outer pack, are unknown. Wind erosion may be substantially curtailed here by widespread surface melt. Finally, we have not explicitly accounted for the morphology of the ice. Deeper snow is often found in the vicinity of deformed ice (e.g. Massom and others, 2006; Lewis and others, in press), demonstrating that ridges will capture snow before it can be lost into leads. Nevertheless, both the observational and model results presented here suggest that snowdrift plays an important role in the mass balance of snow-covered sea ice in the Antarctic.

\section{CONCLUSIONS}

Significant wind erosion of snow occurred during the SIMBA sea-ice drift experiment in the Bellingshausen Sea during the austral spring of 2007. Field measurements of precipitation rate, blowing-snow frequency, winds and snow accumulation demonstrated that falling snow was rapidly eroded from level ice surfaces at a wide range of wind speeds. Numerical snowdrift model results, driven by ERA interim data for this period and scaled by observed drifting-snow frequency during SIMBA, were applied to the entire Southern Ocean sea-ice domain to create maps of precipitation and net accumulation of snow that qualitatively appear to partially resolve several important questions raised by earlier studies of snow accumulation on Antarctic sea ice. The results of this preliminary regional analysis suggest that the high erosion rates of snow observed during the SIMBA experiment were not a regional anomaly but occur throughout the Antarctic, and in some areas may be of similar magnitude to precipitation.

\section{ACKNOWLEDGEMENTS}

US National Science Foundation (NSF) Office of Polar Programs grants ANT-0703682 to S. Ackley and ANT-0632282 to $\mathrm{S}$. Jacobs supported the fieldwork during the SIMBA project, as did a grant to $\mathrm{K}$. Leonard from the Lamont-Doherty Earth Oservatory (LDEO) Climate Center. Funding from the Swiss National Science Foundation supported the data analysis. We thank S. Ackley, B. Elder, C. Fritsen, E. Johnson, J. Lucke, B. McKee, V. Shen and S. Stammerjohn for field and technical assistance during the SIMBA cruise, and M. Watson and the Edison Chouest Offshore (ECO) and Raytheon Polar Services Company personnel aboard the NBP. ECMWF operational forecast fields for September and October 2007 were obtained from the US National Center for Atmospheric Research (NCAR), while ERA interim fields were obtained from the ECMWF (http://www.ecmwf.int/research/era/do/get/era-interim). Helpful comments from reviewers and colleagues including R. Bintanja, A. Clifton, S. Déry, M. Lehning and M. Sturm led to significant improvements in the manuscript. This is Lamont-Doherty Earth Observatory contribution No. 7408.

\section{REFERENCES}

Ackley, S.F. and C.W. Sullivan. 1994. Physical controls on the development and characteristics of Antarctic sea ice biological communities - a review and synthesis. Deep-Sea Res. I., 41(10), 1583-1604.
Andreas, E.L. and 6 others. 2002. Near-surface water vapor over polar sea ice is always near ice saturation. J. Geophys. Res., 107(C10), 8033. (10.1029/2000JC000411.)

Bagnold, R.A. 1954. The physics of blowing sand and desert dunes. Second edition. London, Chapman and Hall.

Bintanja, R. and C.H. Reijmer. 2001. A simple parameterization for snowdrift sublimation over Antarctic snow surfaces. J. Geophys. Res., 106(D23), 31,739-31,748.

Bromwich, D.H. 1988. Snowfall in high southern latitudes. Rev. Geophys., 26(1), 149-168.

Brown, T. and J.W. Pomeroy. 1989. A blowing snow particle detector. Cold Reg. Sci. Technol., 16(2), 167-174.

Comiso and Nishio, J.C. 2008. Trends in the sea ice cover using enhanced and compatible AMSR-E, SSM/I, and SMMR data. J. Geophys. Res., 113(C2), C02S07. (10.1029/2007JC004257.)

Déry, S.J. and L.-B. Tremblay. 2004. Modeling the effects of wind redistribution on the snow mass budget of polar sea ice. J. Phys. Oceanogr., 34(1), 258-271.

Eicken, H., M.A. Lange, H.W. Hubberten and P. Wadhams. 1994. Characteristics and distribution patterns of snow and meteoric ice in the Weddell Sea and their contribution to the mass balance of sea ice. Ann. Geophys., 12(1), 80-93.

Fichefet, T. and M.A. Morales Maqueda. 1999. Modelling the influence of snow accumulation and snow-ice formation on the seasonal cycle of the Antarctic sea-ice cover. Climate Dyn., 15(4), 251-268.

Fichefet, T., B. Tartinville and H. Goosse. 2000. Sensitivity of the Antarctic sea ice to the thermal conductivity of snow. Geophys. Res. Lett., 27(3), 401-404.

Haas, C., D.N. Thomas and J. Bareiss. 2001. Surface properties and processes of perennial Antarctic sea ice in summer. J. Glaciol., 47(159), 613-625.

lacozza, J. and D.G. Barber. 2010. An examination of snow redistribution over smooth land-fast sea ice. Hydrol. Process., 24(7), 850-865.

Jeffries, M.O., H.R. Krouse, B. Hurst-Cushing and T. Maksym. 2001. Snow-ice accretion and snow-cover depletion on Antarctic firstyear sea-ice floes. Ann. Glaciol., 33, 51-60.

Klinker, E., F. Rabier, G. Kelly and J.F. Mahfouf. 2000. The ECMWF operational implementation of four-dimensional variational assimilation. Part III: Experimental results and diagnostics with operational configuration. Q. J. R. Meteorol. Soc., 126(564), 1191-1215.

Knuth, S.L., G.J. Tripoli, J.E. Thom and G.A. Weidner. 2010. The influence of blowing snow and precipitation on snow depth change across the Ross Ice Shelf and Ross Sea regions of Antarctica. J. Appl. Meteorol. Climatol., 49(6), 1306-1321.

Leonard, K.C. and R.I. Cullather. 2008. Snowfall measurements in the Amundsen and Bellingshausen Seas, Antarctica. In Proceedings of the 65th Eastern Snow Conference, 28-30 May 2008, Fairlee, Vermont, USA. Hanover, NH, US Army Cold Regions Research and Engineering Laboratory.

Leonard, K.C., L.-B. Tremblay, D.R. MacAyeal and S.S. Jacobs. 2008. Interactions of wind-transported snow with a rift in the Ross Ice Shelf, Antarctica. Geophys. Res. Lett., 35(L5), L05501. (10.1029/2007GL033005.)

Lewis, M.J. and 6 others. In press. Sea ice and snow cover characteristics during the winter-spring transition in the Bellingshausen Sea: an overview of SIMBA 2007. Deep-Sea Res. II. (10.1016/j.dsr2.2010.10.027.)

Li, L. and J.W. Pomeroy. 1997. Estimates of threshold wind speeds for snow transport using meteorological data. J. Appl. Meteorol., 36(3), 205-213.

Macpherson, T., W.G. Nickling, J.A. Gillies and V. Etyzemezian. 2008. Dust emissions from undisturbed and disturbed supplylimited desert surfaces. J. Geophys. Res., 113(F2), F02S04. (10.1029/2007JF000800.)

Maksym, T. and M.O. Jeffries. 2000. A one-dimensional percolation model of flooding and snow-ice formation on Antarctic sea ice. J. Geophys. Res., 105(C11), 26,313-26,331. 
Maksym, T. and T. Markus. 2008. Antarctic sea ice thickness and snow-to-ice conversion from atmospheric reanalysis and passive microwave snow depth. J. Geophys. Res., 113(C2), C02S12. (10.1029/2006JC004085.)

Mann, G.W., P.S. Anderson and S.D. Mobbs. 2000. Profile measurements of blowing snow at Halley, Antarctica. J. Geophys. Res., 105(D19), 24,491-24,508.

Markus, T. and D.J. Cavalieri. 1998. Snow depth distribution over sea ice in the Southern Ocean from satellite passive microwave data. In Jeffries, M.O., ed. Antarctic sea ice: physical processes, interactions and variability. Washington, DC, American Geophysical Union, 19-39. (Antarctic Research Series 74.)

Massom, R.A. and 12 others. 2001. Snow on Antarctic sea ice. Rev. Geophys., 39(3), 413-445.

Massom, R. and 17 others. 2006. ARISE (Antarctic Remote Ice Sensing Experiment) in the East 2003: validation of satellitederived sea-ice data products. Ann. Glaciol., 44, 288-296.

Maykut, G.A. and N. Untersteiner. 1971. Some results from a timedependent thermodynamic model of sea ice. J. Geophys. Res., 76(6), 1550-1575.

Pomeroy, J.W. and D.H. Male. 1992. Steady-state suspension of snow. J. Hydrol., 136(1-4), 275-301.

Richter-Menge, J.A., D.K. Perovich, B.C. Elder, K. Claffey, I. Rigor and M. Ortmeyer. 2006. Ice mass balance buoys: a tool for measuring and attributing changes in the thickness of the Arctic sea-ice cover. Ann. Glaciol., 44, 205-210.

Savelyev, S.A., M. Gordon, J. Hanesiak, T. Papakyriakou and P.A. Taylor. 2006. Blowing snow studies in the Canadian Arctic Shelf Exchange Study, 2003-04. Hydrol. Process., 20(4), $817-827$

Sturm, M., K. Morris and R. Massom. 1998. The winter snow cover of the West Antarctic pack ice: its spatial and temporal variability. In Jeffries, M.O., ed. Antarctic sea ice: physical processes, interactions and variability. Washington, DC, American Geophysical Union, 1-18. (Antarctic Research Series 74.)

Vancoppenolle, M. and 10 others. In press. Assessment of radiation forcing data sets for large-scale sea ice models in the Southern Ocean. Deep-Sea Res. II. (10.1016/j.dsr2.2010.10.039.)

Worby, A.P., C.A. Geiger, M.J. Paget, M.L. van Woert, S.F. Ackley and T.L. DeLiberty. 2008. Thickness distribution of Antarctic sea ice. J. Geophys. Res., 113(C5), C05S92. (10.1029/2007JC004254.)

Wu, X., W.F. Budd, V.I. Lytle and R.A. Massom. 1999. The effect of snow on Antarctic sea ice simulations in a coupled atmospheresea ice model. Climate Dyn., 15(2), 127-143.

Xiao, J., R. Bintanja, S.J. Déry, G. Mann and P.A. Taylor. 2000. An intercomparison between three models of blowing snow in the atmospheric boundary layer. Bound.-Layer Meteorol., 97(1), 109-135. 